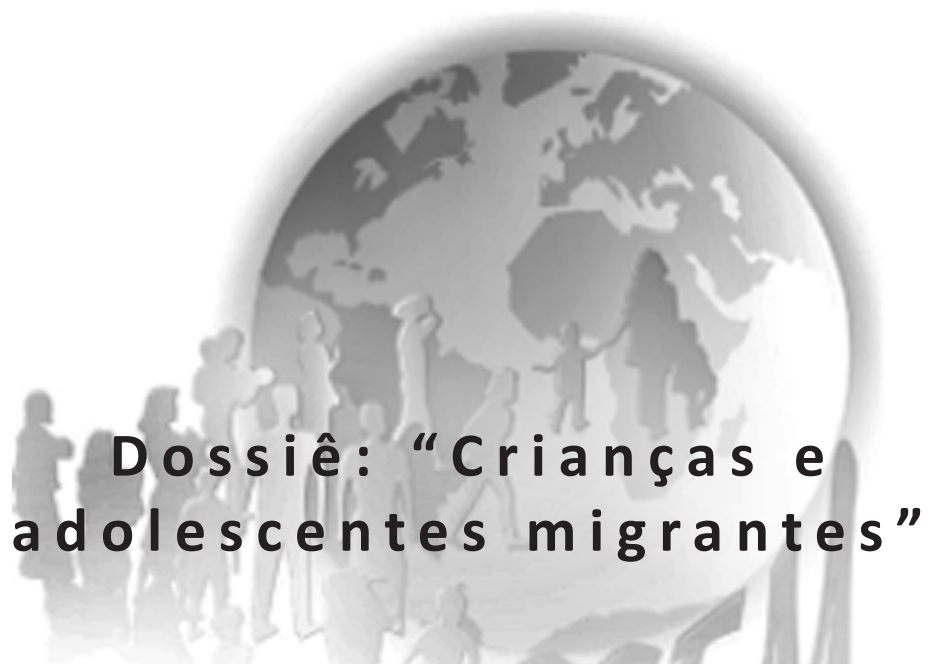

\title{
NIÑEZ Y ADOLESCENCIA EN EL CONTEXTO DE LA MIGRACIÓN: PRINCIPIOS, AVANCES Y DESAFÍOS EN LA PROTECCIÓN DE SUS DERECHOS EN AMÉRICA LATINA $Y$ EL CARIBE
}

\author{
Pablo Ceriani Cernadas* \\ Lila García** \\ Ana Gómez Salas ${ }^{* * *}$
}

\begin{abstract}
El presente artículo busca dar un panorama sobre la situación de la niñez y la adolescencia en América Latina y el Caribe; específicamente, sobre los avances y desafíos actuales que se presentan a los países de la región en materia de los derechos humanos de los niños, niñas y adolescentes (NNA) en el contexto de la migración. Con tal fin, se hace una descripción general sobre el tema con base en algunos principios generales que se derivan de la Convención sobre los Derechos del Niño, a partir de los cuales pueden construirse ciertos estándares concretos aplicables sobre NNA migrantes e hijos/as de migrantes. Luego, se presentan sucintamente dos casos puntuales que dan cuenta precisamente sobre la variedad de contextos, oportunidades y retos sobre la temática en la región: Argentina y México.
\end{abstract}

Palabras clave: migración, derechos humanos, niños/as, América Latina.

Coordinador del Programa Migración y Asilo del Centro de Derechos Humanos de la Universidad Nacional de Lanús/Argentina.

** Investigadora del Programa Migración y Asilo del Centro de Derechos Humanos de la Universidad Nacional de Lanús/Argentina.

*** Investigadora del Programa Migración y Asilo del Centro de Derechos Humanos de la Universidad Nacional de Lanús/Argentina. 


\section{Introducción}

Un punto de partida común al hablar de migraciones es que en la actualidad existen más personas viviendo fuera de su país de nacimiento que en ningún otro momento de la historia ${ }^{1}$, característica notada ya en la etapa posterior a la Guerra Fría ${ }^{2}$.

Mientras que a nivel global se estima que hay alrededor de 230 millones que viven fuera del país de origen, en el caso de América Latina y el Caribe se calculaba - en 2006 - que unos 25 millones de migrantes vivían en Norteamérica y Europa, mientras que otros 6 millones habían migrado entre países de la región ${ }^{3}$. Se trata mayoritariamente de población joven, ya que los menores de 20 años de edad son el grupo más importante del total. A nivel global, en África los y las jóvenes representan el 27\% del total, seguido por América Latina y el Caribe (19\%), Asia (17\%), Oceanía (15\%) y Europa y América del Norte (11\%). Entre migrantes menores de 20 años, aquellos entre 15 y 19 alcanzan el 34\%, y el grupo de entre 10 y 14 años representa el $26 \%{ }^{4}$.

Es altamente probable que este importante número de NNA migrantes, a la luz de algunos datos más actualizados sobre la migración en la región latinoamericana, se haya incrementado notablemente. Los estudios más recientes en torno a la migración de niños y niñas no acompañados en Centro y Norte América, indican un crecimiento de entre un 300 o 400\% entre 2011 y $2014^{5}$.

Ahora bien, a estos números hay que sumarle otras categorías de niños, niñas y adolescentes cuyas vidas, y derechos, también se ven afectados por la migración y las políticas para regular la movilidad internacional y los derechos de las personas migrantes. Entre las diferentes categorías de NNA en el contexto de la migración, es posible incluir al menos las siguientes:

$\checkmark$ Niños, niñas y adolescentes que permanecen en su país de origen: se trata de hijos e hijas de padres que han migrado a otro país.

$\checkmark$ Niños, niñas y adolescentes no acompañados o separados" : los "niños no

ZLOTNIK, Hania. Tendencias de la migración internacional desde 1980.

2 CASTLES, Stephen; MILLER, Mark. La era de la migración, p. 11.

3 CEPAL. Migración internacional, derechos humanos y desarrollo.

4 Datos de la Base de datos sobre Migraciones sobre Naciones Unidas: <http://esa.un.org/ unmigration/>. Acceso el 31 de marzo de 2014.

5 Entre otros, ver: ACNUR. Children on the Run. Unaccompanied Children Leaving Central America and Mexico and the Need for International Protection; CERIANI CERNADAS, Pablo (coord.). Niñez Detenida. Los derechos de niños, niñas y adolescentes migrantes en la frontera México-Guatemala.

6 Para profundizar en los estándares legales respecto a esta categoría ver Comité de Derechos del Niño de Naciones Unidas. Trato de los menores no acompañados y separados de su familia fuera de su país de origen. Observación General, n. 6, 30o período de sesiones, CRC/GC/2005/6, 17 Mayo-3 Junio 2005. 
acompañados" están separados de ambos padres y otros parientes y no están al cuidado de un adulto al que, por ley o costumbre, incumbe esa responsabilidad". En cambio, los "niños separados" no migran con sus padres o tutores legales, pero sí junto a otros parientes ${ }^{8}$.

$\checkmark$ Niños, niñas y adolescentes que migran con sus padres: son aquellos NNA que se movilizan a través de las fronteras internacionales junto con sus padres (o tutores) o uno de ellos.

$\checkmark \quad$ Niños, niñas y adolescentes nacidos en destino: niños que nacen en el país en el que residen sus padres. Según el criterio que rige en ese país y en el de origen (ius sanguinis o ius soli), pueden tener la nacionalidad de sus padres y/o la nacionalidad del país de destino.

$\checkmark$ Niños, niñas y adolescentes retornados: son NNA migrantes o nacidos en el país de destino de padres migrantes, que regresan a su país de origen (o el de sus padres), solos o acompañados, de forma voluntaria o como consecuencia de un procedimiento de deportación o repatriación.

De esta manera, y aunque no se cuentan con estadísticas precisas y desagregadas al respecto ${ }^{9}$, puede afirmarse que la cantidad de NNA "en el contexto de la migración" es sin dudas considerablemente relevante. A pesar del volumen de personas menores de 18 años cuyos derechos están directa o indirectamente determinados por las políticas migratorias, así como del crecimiento de NNA estrictamente migrantes, esta temática presenta aún hoy en día un alto nivel de invisibilidad, particularmente en cuanto a las políticas públicas que se implementan en materia de niñez y de migración. Por ello se habla de una doble invisibilidad.

Por un lado, hay una falta de perspectiva de la infancia en la política migratoria, la cual resulta en medidas inadecuadas desde un enfoque de derechos de NNA. Sin perjuicio de las diferencias de país a país, y de algunos avances que luego destacaremos, esta omisión es "un rasgo común en las políticas migratorias en la región ${ }^{\prime 10}$. Esto repercute en cuestiones esenciales tales como la primacía de los objetivos de las políticas migratorias sobre la protección de la infancia, la inexistencia de información sobre el impacto del proceso migratorio en NNA, la insuficiencia de los programas de capacitación en niñez y derechos humanos y la muy escasa aplicación de los estándares sobre derechos de niños y niñas en la legislación y la política migratoria (por ejemplo, en lo relativo a la expulsión o la detención de migrantes).

Ibidem, § 7 .

8 Ibidem, §8.

9 MERCOSUR, Instituto de Políticas Públicas en Derechos Humanos (IPPDH). Solicitud de Opinión Consultiva ante la Corte IDH, 6 de abril de 2011, párr. 2.1.

${ }^{10}$ UNLa-UNICEF. Estudio sobre los estándares jurídicos básicos aplicables a niños y niñas migrantes en situación migratoria irregular en América Latina y el Caribe. 
Por otro lado, las políticas de infancia no han incorporado debidamente la temática migratoria, es decir, que tenga en consideración los múltiples nexos entre ambas cuestiones. A modo de ejemplo, las falencias o fracasos de una política de protección integral de la infancia en países de origen de migración, puede llevar a un incremento en el número de NNA que migran, solos o con sus familias, y luego, a dificultar su retorno y reintegración adecuada. Del mismo modo, en países de destino, la indebida o limitada inclusión de las necesidades de NNA migrantes o hijos/as de migrantes en las políticas de infancia, puede conducir a situaciones de desigualdad y discriminación, o incluso a la separación familiar u otros perjuicios como consecuencia de la aplicación de mecanismos de control migratorio.

Para completar esta introducción, es importante mencionar que en el escenario actual, la migración irregular se ha convertido progresivamente en una característica central de los flujos migratorios ${ }^{11}$. Si partimos del carácter históricamente estructural de la vinculación entre migración y capitalismo, hoy en día es posible afirmar que la migración irregular (salida, entrada o permanencia irregular) ha ido incrementándose de manera paralela al crecimiento de la demanda de trabajo desprotegido y precario en las áreas informales o sumergidas de la economía de los países de destino. En este contexto han florecido las políticas migratorias restrictivas que, por un lado, reducen las opciones de migración regular (entre otras vías, por reunificación familiar) y por el otro, estimulan o perpetúan mecanismos irregulares (incluyendo con redes de tráfico de personas).

En definitiva, las circunstancias en que se encuentra la mayoría de NNA migrantes o hijos/as de migrantes son de elevada vulnerabilidad. Tanto las causas que llevan a su migración como las diferentes restricciones, peligros o abusos a sus derechos en países de tránsito y destino, conforman un panorama complejo que se agrava en el caso de NNA no acompañados, particularmente si están en situación migratoria irregular. El viaje en solitario por parte de NNA, en muchos casos de corta edad, sumado a la de la inexistencia de canales regulares y seguros de migración, los expone a una multiplicidad de situaciones de abuso o persecución, los que como se mencionó, combinados con otras categorías, tales como la edad, el género, clase social y etnicidad, dan como resultado formas particularmente graves de desprotección y riesgo a su vida e integridad física. Ello supone importantes desafíos a los Estados

11 Al respecto, ver IZQUIERDO, Antonio. Cuatro razones para pensar en la inmigración irregular. Ver también los Informes del Relator Especial sobre los derechos humanos de los migrantes, A/65/222, 2010 y A/HCR/17/33, 2011; y OIM. El futuro de la migración: creación de capacidades para el cambio, 2010. 
de origen, tránsito y destino a los fines de buscar soluciones que aseguren un tratamiento adecuado de protección y acceso a derechos de NNA que transitan por sus territorios.

En la sección siguiente describiremos algunos aspectos generales sobre la situación de los derechos de NNA en el contexto de la migración en América Latina y el Caribe, sobre la base de algunos principios de derechos humanos claves a tener en cuenta en esta temática.

\section{Niñez y migración en América Latina y el Caribe: tendencias generales}

En materia de políticas migratorias, es posible afirmar que la región de ALC se encuentra en un proceso de transición, hacia un abordaje más integral y centrado en los derechos. De todos modos, se trata de una transición que se caracteriza por su complejidad, sus diferentes velocidades, así como por una serie de contradicciones y desafíos serios. Igualmente, en líneas generales, es posible señalar que la región ha ido progresivamente incorporando un enfoque de derechos humanos en sus políticas migratorias, destacándose especialmente algunos países sudamericanos, dejando de lado - parcialmente, en algunos casos - la visión securitaria como el elemento central de las políticas migratorias.

Evidencia de este nuevo escenario son las declaraciones adoptadas en diversos ámbitos regionales, como la Conferencia Sudamericana de Migraciones, la UNASUR, o el Foro Iberoamericano sobre Migración y Desarrollo. También, las leyes migratorias de Argentina, Bolivia y Uruguay, o la Constitución ecuatoriana. Otros cambios normativos, aunque significan un avance respecto de la ley anterior, aún presentan varios retos, como lo atestiguan los casos de Costa Rica, México y Panamá. Los proyectos de ley en Brasil y Chile, que buscan para reemplazar leyes desfasadas y claramente restrictivas, siguen aún esta línea ambigua. Sin agotar todos los ejemplos, cabe mencionar a países con leyes basadas en enfoques securitarios, que no han incorporado obligaciones de derechos humanos (como sucede en varios países del Caribe), o que incluso han incluido medidas regresivas, como es el caso de República Dominicana ${ }^{12}$.

Ahora bien, aún en el contexto de los avances que se han dado en varios países de la región, se puede afirmar que estos cambios no han contemplado, o bien lo han hecho de manera parcial, la situación especial de 12 Para mayor detalle véase CERIANI, Pablo. Luces y sombras en la legislación migratoria
latinoamericana. 
las diversas categorías de NNA afectados por la migración. Aunque es cierto que poco a poco se ha ido visibilizado el fenómeno de la niñez migrante, lo que ha derivado en algunas medidas o programas concretos - en algunos países -, en líneas generales se verifica que dicha perspectiva está ausente en las políticas, las leyes y las prácticas que regulan los diferentes aspectos de la migración.

En este marco, nos parece importante señalar algunas problemáticas, discusiones o modificaciones concretas que se han dado en la región, sobre la base de los principios y de derechos de niños, niñas y adolescentes. Específicamente, tomando en cuenta los estándares principales que surgen de la fuente normativa más importante en el tema, la Convención Internacional sobre los Derechos del Niño (CDN), "traduciremos" algunos de estos principios al ámbito migratorio, es decir, a cómo deberían interpretarse y aplicarse cuando se trata de NNA migrantes o hijos e hijas de migrantes.

A partir del desarrollo interpretativo de la CDN, los cuatro principios rectores en materia de derechos de NNA son: el principio de no discriminación (art. 2, CDN); el interés superior del niño (art. 3, CDN); el derecho a la vida y al desarrollo; y el derecho a la participación y a ser oído. Es a partir del uso general de estos principios, y su aplicación en determinadas situaciones, que se pueden extraer algunos estándares particularmente relevantes en el caso de NNA en el contexto de la migración.

a) El Principio de no discriminación. Este principio clave del Derecho International de los Derechos Humanos, que debe aplicarse transversalmente a todos y cada uno de los derechos humanos, ha tenido un reconocimiento particularmente importante en el caso de NNA, ya que la CDN es tajante en cuanto a no permitir restricción o distinción alguna sobre la base de cualquier condición del niño o de sus padres. Ello debería impedir, entonces, un trato diferencial en los derechos de un niño o niña debido a su nacionalidad o condición migratoria, o la de sus padres.

En esta línea, el Comité de Derechos, Económicos, Sociales y Culturales, reconoce expresamente que la obligación de los Estados de respetar el derecho a la salud implica abstenerse de denegar o limitar el acceso igual de todas las personas, incluidos, los solicitantes de asilo o los inmigrantes sin documentación ${ }^{13}$. En el mismo sentido, la más reciente Observación General 20 del mismo Comité, establece que no se podrá impedir el acceso a los derechos amparados en el Pacto por razones de nacionalidad, por ejemplo, todos los

${ }^{13}$ COMITÉ de Derechos Económicos, Sociales y Culturales. Observación General 14: El derecho al disfrute del más alto nivel posible de salud (artículo 12), E/C.12/1999/10, del 8 de diciembre de 1999, párr. 34. 
niños de un Estado, incluidos los indocumentados, tienen derecho a recibir una educación y una alimentación adecuada y una atención sanitaria asequible. Finalmente afirma que "...los derechos reconocidos en el Pacto son aplicables a todos, incluidos los no nacionales, como los refugiados, los solicitantes de asilo, los apátridas, los trabajadores migratorios independientemente de su condición jurídica y de la documentación que posean"14.

Sin embargo, NNA migrantes o hijos/as de migrantes pueden ver restringidos una amplia gama de derechos civiles y sociales debido a su status migratorio o el de sus padres. Sólo a modo de ejemplo, puede mencionarse situaciones como las siguientes: 1) la aplicación de medidas administrativas de la libertad por razones de índole administrativa, en contraposición con los estándares generales que rigen para la detención de NNA (como veremos en el caso de México); 2) las restricciones en el ejercicio de derechos como la salud o la educación; y 3) los obstáculos a la inscripción del nacimiento, el derecho a un nombre y a una nacionalidad, con especial intensidad en el caso de República Dominicana.

Al contrario, el reconocimiento de la igualdad de derechos sociales en leyes como las de Argentina, Bolivia o Uruguay, con independencia de la condición migratoria, contribuye al diseño de políticas migratorias que contemplan principios claves como el de no discriminación. De todas maneras, la ausencia de una mención específica a los NNA puede dificultar una aplicación más eficaz y apropiada de un marco normativo favorable.

b) El Principio de interés superior del niño. La CDN refiere en su artículo 3 que "en todas las medidas concernientes a los niños que tomen las instituciones públicas o privadas de bienestar social, los tribunales, las autoridades administrativas o los órganos legislativos, una consideración primordial a que se atenderá será el interés superior del niño". En el ámbito migratorio, este principio debería ser el que guía cualquier programa, política o decisión que pueda impactar en los derechos de un niño, niña o adolescente. En este sentido, a modo de ejemplo, el principio de interés superior del niño, al ser aplicado en el contexto de las políticas migratorias, debería ser determinante en cuestiones como las siguientes:

$\checkmark$ Autorizar el acceso al territorio y la concesión de un permiso de residencia a NNA migrantes no acompañados y familias migrantes;

$\checkmark$ Disponer el retorno al país de origen de NNA migrantes no acompañados;

$\checkmark$ Diseñar programas de integración social de NNA migrantes (acompañados

${ }^{14}$ COMITÉ de Derechos Económicos, Sociales y Culturales. Observación General 20: La no discriminación y los derechos económicos, sociales y culturales. E/C.12/GC/20. 2 de julio de 2009, párr. 30. 
o no) en el país de destino, asegurando el acceso sin discriminación a todos los derechos;

$\checkmark$ Decidir el reasentamiento en un tercer país de NNA migrantes, solicitantes de asilo o refugiados;

$\checkmark$ Facilitar la reunificación familiar, en el país de origen, tránsito o destino, según las circunstancias de cada caso particular;

$\checkmark$ Promover la regularización migratoria de NNA migrantes, familias migrantes, y padres de niños/as nacidos en el país de destino;

$\checkmark$ Abstenerse de expulsar del país a adultos migrantes si ello deriva en la separación familiar, y tal separación no se dispone en el interés superior;

$\checkmark$ Garantizar medidas alternativas a la privación de la libertad de NNA migrantes y familias migrantes;

$\checkmark$ Abstenerse de privar de la libertad a adultos migrantes en razón de su condición migratoria, en caso que residan con sus hijos/as;

$\checkmark$ Diseñar y aplicar - caso a caso - medidas de protección especial a NNA migrantes víctimas de delitos, como la trata, explotación, abusos y violencia, entre otros;

$\checkmark$ Implementar programas de asistencia consular que incluyan la debida formación en derechos del niño de los agentes consulares.

El diagnóstico sobre la situación de los NNA migrantes e hijos de migrantes en la región, sin perjuicio de la ausencia de información suficiente y de la diversidad de realidades de país a país, da cuenta de un amplio número de desafíos pendientes en materia de aplicación adecuada del principio de interés superior del niño. Al contrario, cuando se trata de políticas migratorias, parecería que hay un interés superior al niño, es decir, que los derechos parecerían quedar supeditados a objetivos supuestamente prioritarios, como la reducción de la migración irregular, o la presunta reducción del gasto en salud o educación.

c) El derecho a ser oído. La participación del NNA en los asuntos que le conciernen, es decir, y especialmente en los procedimientos que pueden derivar en decisiones que impacten en sus derechos, es un principio fundamental de la CDN. De acuerdo con su edad y madurez, con base en el principio de autonomía progresiva que se deriva del artículo 5 de la Convención, el derecho a ser oído (art. 12 CDN) puede ser una parte clave de un proceso. En el plano migratorio, esto cobra vital relevancia en, por ejemplo, procedimientos que pueden derivar en la detención o expulsión de un NNA y/o sus padres, así como en la separación familiar.

En la región, prácticamente ningún país cuenta con el reconocimiento normativo ni con los dispositivos prácticos dirigidos a garantizar este derecho en 
el marco de procedimientos de índole migratoria ${ }^{15}$. En algunos casos, es posible que las decisiones tomen en consideración aspectos relativos a los derechos de NNA que podrían estar en juego, pero no necesariamente contemplan la participación del niño o niña a lo largo del proceso, reduciendo así un cambio medular del paradigma que emana de la CDN: el niño como sujeto pleno de derechos.

d) El derecho al desarrollo. El derecho de un niño o niña a un nivel de vida adecuado, esto es, a desarrollarse física, psíquica y emocionalmente a partir del ejercicio de los derechos fundamentales, no sólo está reconocido en el art. 4 CDN, sino - podríamos decir - a lo largo de toda la Convención. Se trata de asegurar condiciones de vida digna, apropiadas y sin discriminación alguna, a todo niño, niña y adolescente.

Una simple aproximación a la situación de los y las migrantes - a nivel global y regional - basta para evidenciar los enormes desafíos en materia de derecho al desarrollo de los NNA. Por un lado, entre las principales causas de la migración de NNA, familias, o incluso de los padres solamente, está precisamente la no satisfacción de un adecuado desarrollo a los niños y niñas, el fracaso de las políticas de protección de infancia y otras políticas sociales. Por otro lado, las condiciones de vulnerabilidad en que se encuentran las familias migrantes en países de tránsito y destino, y en especial la desigualdad que enfrentan en el acceso a derechos como la salud, educación, vivienda o trabajo, contribuye a restringir el derecho a una vida adecuada de los NNA migrantes y los hijos e hijas de migrantes.

En igual sentido, las múltiples formas en que es afectado el derecho a la vida familiar de los NNA - pese a la fuerte protección brindada por la CDN a este derecho -, por razones de índole migratoria, es otra de las formas en que se manifiesta la vulneración del derecho al desarrollo de NNA migrantes e hijos/as de migrantes ${ }^{16}$.

e) El principio de primacía de la protección de la infancia. Un corolario lógico de la aplicación en el ámbito migratorio del principio de interés superior del niño es que todos los derechos de la CDN, esto es, la protección integral de la infancia, debe primar sobre cualquier objetivo o interés de la política migratoria, tal como lo ha señalado UNICEF ${ }^{17}$. En palabras del

\footnotetext{
${ }^{15}$ Ver al respecto UNLA-UNICEF, Estudio... op. cit.

${ }^{16}$ Ver al respecto, CERIANI y otros. Migraciones y el Derecho a la vida familiar de niños, niñas y adolescentes.

17 UNICEF. Observación Escrita presentada ante la Corte Interamericana de Derechos Humanos, en el marco de la Opinión Consultiva sobre Niñez y Migración presentada por los Estados del Mercosur. Disponible en: <http://www.unicef.org/argentina/spanish/resources_10849.htm>.
} 
Alto Comisionado de las Naciones Unidas para los Derechos Humanos ha señalado, "...todas las autoridades e instituciones que entren en contacto con niños en el contexto de la migración deberán determinar que la protección de los intereses de cada niño sea una consideración primordial en sus acciones. Este principio debería prevalecer sobre todos los demás, incluidas las disposiciones contrarias de la normativa sobre migración en caso de que se planteara un conflicto"18.

La protección especial que los Estados deben garantizar a los niños, niñas y adolescentes parte del reconocimiento de que éstos tienen necesidades diferenciadas a las de los adultos ${ }^{19}$, que deben ser satisfechas con la finalidad de que puedan desarrollar sus capacidades y ejercer sus derechos plenamente. La nacionalidad del NNA, o una cuestión administrativa como su status migratorio, debería ser absolutamente irrelevante para el cumplimiento de esas obligaciones. En su caso, al contrario de lo que sucede usualmente en la práctica, la condición migratoria o la nacionalidad del niño o niña, debería ser contemplada para, precisamente, revertir posibles situaciones de vulnerabilidad o discriminación, y no para justificar un trato desigual o discriminatorio.

f) El Principio de no privación de la libertad. Con base en los estándares del DIDH, la privación de la libertad - como medida cautelar - en el marco de un procedimiento penal es una medida estrictamente excepcional. En el caso de NNA, según el artículo 37.2 CDN, en procesos de índole criminal, la detención debe ser una medida de último recurso.

Por lo tanto, en procedimientos migratorios (es decir, a raíz de una eventual irregularidad administrativa, como un ingreso irregular al territorio, o el vencimiento de un permiso de residencia), la privación de la libertad no debería aplicarse en ningún caso $^{20}$. Asimismo, en tanto la detención de NNA no podría estar justificada nunca en el interés superior, se ha argumentado que en el caso de familias migrantes, se debería recurrir a medidas alternativas a la detención a favor de todo el grupo familiar, antes que a justificar la detención de un niño o niña invocando el principio de la unidad familiar ${ }^{21}$.

${ }_{18} \mathrm{OACDH}$. Estudio de la Oficina del Alto Comisionado de las Naciones Unidas para los Derechos Humanos sobre los problemas y las mejores prácticas en relación con la aplicación del marco internacional para la protección de los derechos del niño en el contexto de la migración. A/ HRC/15/29, 5 de julio de 2010, párr. 24.

${ }^{19}$ Corte IDH, Condición Jurídica y Derechos Humanos del Niño. Opinión Consultiva OC-17/02 de 28 de agosto de 2002. Serie A No. 17, párr. 96.

${ }^{20}$ COMITÉ de Derechos del Niño, Background Paper. Día de Discusión General sobre los Derechos de todos los niños, niñas y adolescentes en el contexto de la migración, septiembre de 2012. Disponible en: < http://www.ohchr.org/EN/HRBodies/CRC/Pages/Discussion2012.aspx>. En igual sentido, ver UNICEF. Observación Escrita..., op. cit.

${ }^{21}$ Ibidem. 
En la región, mientras que son una excepción las normas que prohíben la detención de NNA en procesos migratorios (como Panamá), casi ninguno ha diseñado medidas alternativas a la detención de familias, y prácticamente no hay excepciones a la detención de adultos a fin de evitar la separación familiar con sus hijos/as. Ahora bien, también es importante mencionar que algunos países no permiten la detención siquiera de adultos por razones migratorias (Uruguay, Venezuela), y en otros existe un principio de no detención (Argentina, México), aunque aquí veremos que las prácticas varían mucho según cada país ${ }^{22}$.

g) El Principio de no expulsión. Otro de los corolarios más importantes de la adecuada inclusión del interés superior a las políticas migratorias, es la necesidad de que los Estados se abstengan de expulsar o repatriar a un niño o niña migrante como medida sancionatoria ante la irregularidad migratoria. Así, cualquier medida que suponga el traslado de un NNA hacia otro país (el país de origen o un tercero), debe constituir una medida basada en el interés superior.

En palabras del Comité de Derechos del Niño, "el retorno al país de origen podrá decidirse una vez ponderados debidamente el interés superior del menor y otras consideraciones, si estas últimas están fundadas en derechos y prevalecen sobre el interés superior del menor (...). Los argumentos no fundados en derechos, por ejemplo, los basados en la limitación general de la inmigración, no pueden prevalecer sobre las consideraciones fundadas en el interés superior"23. En idéntico sentido, el Relator de Naciones Unidas sobre Derechos de Migrantes ha cuestionado las políticas que aceptan la deportación de niños y niñas migrantes como medida de "castigo", en lugar de que la repatriación responda únicamente a criterios basados y debidamente fundamentados, en cada caso, en un enfoque de protección de la niñez ${ }^{24}$.

Son muy escasos los países en que han incluido esta cuestión en su normativa. El Código de la Niñez y Adolescencia de Costa Rica (1998) dispone en su articulo 17 que las "personas menores de edad no serán sujetos de rechazo, deportación ni expulsión del territorio nacional, salvo en resguardo de su propio interés, de acuerdo con los criterios determinados por el interés superior de este grupo". Mientras que México ha sido el único que ha incluido el deber de establecer un Procedimiento de Determi-

\footnotetext{
22 Para un mayor desarrollo sobre la detención de NNA migrantes, ver UNLA-UNICEF, Estudio..., op. cit.

${ }^{23}$ COMITÉ de los Derechos del Niño. Observación General Nro. 6, op. cit., párr. 86.

${ }^{24}$ RELATOR de Naciones Unidas sobre los Derechos Humanos de los Migrantes. Informe presentado al Consejo de Derechos Humanos, A/HRC/11/7, del 14 de mayo de 2009, párr. 57.
} 
nación del Interés Superior del Niño (Ley de Migración, 2011, art. 74), en la práctica, como veremos a continuación, aún no ha tenido aplicación.

\section{Dos casos particulares: Argentina y México}

\subsection{Detenciones y Expulsiones de NNA Migrantes en México}

México se caracteriza por ser un país de origen, tránsito y destino de la migración. En los últimos años se han llevado a cabo una serie de reformas tanto a nivel constitucional como en la normativa migratoria. Pese a ello, la política migratoria contiene numerosas contradicciones. Por un lado, se reconocen derechos de las personas migrantes en consonancia con la postura que tiene el estado en el ámbito internacional, de defensa de sus nacionales en el exterior ${ }^{25}$. Por el otro, sigue primando una política migratoria centrada en una lógica securitaria vinculada a la seguridad nacional, la cual legitima un trato que vulneran los principios, estándares y obligaciones internacionales y constitucionales que consagran esos derechos humanos. En este contexto, la migración se produce en condiciones de alta vulnerabilidad, que impacta con especial intensidad en los NNA.

La Constitución Política de México (CPEUM), reformada en 2011, incorporó la prohibición general de discriminación (artículo 1) y consagra el principio del Interés Superior de la niñez (artículo 4). Por su parte, la Ley de Migración, del mismo año, avanza en un paulatino reconocimiento de diversos principios de derechos humanos para las personas migrantes. Establece, entre otros principios: i. el respeto irrestricto de los derechos humanos de los migrantes, nacionales y extranjeros, con especial atención a grupos vulnerables, ii. la no criminalización de la situación migratoria irregular, estableciendo que, en ningún caso preconfigurará por sí misma la comisión de un delito; iii. la equidad entre nacionales y extranjeros; iv. el reconocimiento a los derechos adquiridos de los migrantes; v. la unidad familiar e interés superior del NNA. Asimismo incluye la obligación de elaborar un procedimiento de determinación del interés superior para NNA no acompañados (art 74), que fuera luego contemplado en el reglamento de la normativa (arts. 169 al 177).

En relación a los NNA migrantes y particularmente a aquellos que lo hacen de manera no acompañada, se han desarrollado diversos mecanismos de protección, los cuales si bien representan cierto avance frente a la invisibilidad

\footnotetext{
${ }^{25}$ A modo de ejemplo en el ámbito del Sistema Interamericano de Derechos Humanos el estado mexicano fue promotor de las solicitudes de Opiniones Consultivas a la Corte IDH, que derivaron en las OC-16/99, sobre el derecho a la asistencia consular, y la OC-18/03, sobre la Condición Jurídica y los Derechos de los Migrantes Indocumentados.
} 
que antes tenía este fenómeno ${ }^{26}$, tienen a ser claramente ineficaces, desde una perspectiva de derechos. Existen obstáculos importantes para que ésas u otras medidas puedan tener un impacto real en los derechos de NNA migrantes.

El problema central está, en primer lugar, en la primacía de la política migratoria - en especial, su visión securitaria - por sobre la política de protección integral de la niñez migrante. Los mecanismos de control migratorio no sólo contribuyen a reforzar los riesgos inherentes a la migración irregular, sino que afectan los mecanismos de la detención y la repatriación de NNA migrantes hacia sus países de origen, utilizados como regla general, sin las garantías del debido proceso y sin la debida consideración de su interés superior en cada caso.

En segundo lugar, la falta de un enfoque de protección integral a NNA migrantes está dado no sólo por el rol subsidiario que les asiste a los organismos responsables de protección de la infancia a nivel local y nacional (Sistemas DIF), dentro de los procedimientos migratorios que involucran a NNA. También, por el carácter profundamente asistencialista, tutelar, de la política general en materia de infancia en México. Un ejemplo paradigmático es la creación de los Oficiales de Protección de la Infancia (OPI). Presentados como el órgano de protección de derechos de NNA migrantes, los OPI, en tanto funcionarios del Instituto Nacional de Migración (INM), su rol más importante está en su contribución al procedimiento de repatriación, sin perjuicio de si se trata o no de la medida más adecuada al interés superior del niño en cada caso.

En este contexto, la respuesta por excelencia ante la migración de NNA a través de territorio mexicano, es su detención y posterior expulsión del país, sin contemplar sus derechos ni garantías básicas, es decir, sin considerar el interés superior del niño. La detención, aplicada a través de eufemismos tales como aseguramiento, presentación, alojamiento, o estancia, ha crecido año tras año, tanto de NNA no acompañados como de familias, sin que se hayan desarrollado medidas alternativas a la detención.

En relación a esta práctica generalizada de detención, los NNA migrantes son detenidos en estaciones migratorias o, excepcionalmente, en albergues

\footnotetext{
${ }^{26}$ Entre esas iniciativas cabe mencionar la creación de los Oficiales de Protección a la Infancia (OPI) y de los Módulos DIF en la Estaciones Migratorias, ambas adoptadas en el seno de la Mesa de Diálogo Interinstitucional sobre NNA no Acompañados y Mujeres Migrantes. También la elaboración, en 2011, del Manual de Referencia del Modelo de Protección de los NNA Migrantes no Acompañados, que contempla una serie de propuestas que de implementarse debida e integralmente, podrían suponer un cambio significativo en el tratamiento de este fenómeno. Para más información CERIANI CERNADAS (coord.), Niñez Detenida..., op. cit.
} 
cerrados del DIF ${ }^{27}$. Ello deriva en un escenario de criminalización de la niñez migrante, la cual, como se mencionó, ocultada bajo practicas de protección de la niñez, atenta seriamente a los principios rectores de la política mexicana, especialmente el principio de no discriminación y el de la utilización de la detención como un recurso de carácter excepcional y sólo para casos de delitos graves (CPEUM, art. 18). Ello también impide la búsqueda de políticas públicas y soluciones integrales y adecuadas en la materia.

Complementariamente, a la detención le sigue una medida de repatriación automática de NNA de manera automática, cuestionada por múltiples estudios e informes ${ }^{28}$, la cual se lleva a cabo sin tener en cuenta la heterogeneidad y multiplicidad de situaciones a ponderar con base en el ISN a los fines de decidir cual es la mejor opción en aras a asegurar su protección. Sumado a ello, la ausencia de mecanismos eficaces de protección consular por parte de los países de origen, así como la falta de políticas de reintegración efectiva con posterioridad a la repatriación (lo que evidencia que no era la medida acorde a su interés superior) ${ }^{29}$, hace que los NNA continúen en la situación de vulnerabilidad de la que intentaron salir a través de la migración y, en muchos casos, vuelvan a exponerse a los riesgos que caracterizan la migración irregular en la región.

\subsection{Argentina: avances en derechos y el desafíode la perspectiva de niñez}

A fines de 2003 se aprobó una ley de migraciones (nro. 25871) que implicó un cambio profundo en el enfoque para tratar las migraciones en la Argentina: de un paradigma securitario el eje se desplaza hacia el reconocimiento de derechos a la persona migrante, particularmente el derecho a migrar que se consagra como inalienable, esencial y garantizado sobre la base de los principios de igualdad y universalidad. Ello, con independencia de su nacionalidad o estatus migratorio.

De conformidad con alguno de los principios enumerados para la $\mathrm{CDN}$, la ley de migraciones incorpora un principio de no discriminación (art. 28) que aunque no menciona la edad, aclara que los motivos mencionados son ejemplos. Asimismo, el reconocimiento del derecho a la educación (art.

\footnotetext{
${ }^{27}$ Para información más detallada, ver CERIANI CERNADAS (coord.), Niñez Detenida..., op. cit.

${ }^{28}$ Por ejemplo: APPLESEAD MEXICO. Niños en la Frontera: Evaluación, Protección y Repatriación de Niños, Niñas y Adolescentes Mexicanos sin Compañía; CATHOLIC RELIEF SERVICES, Niñez migrante. Detención y repatriación...CERIANI CERNADAS (coord.), Niñez Detenida..., op. cit.

${ }^{29}$ Ver al respecto, CASA ALIANZA. Análisis de la situación de Derechos de la Infancia Migrante No Acompañada en el marco de los procedimientos de deportación y retorno a Honduras. Ver también CERIANI CERNADAS (coord.), Niñez Detenida..., op. cit.
} 
7) y a la salud (art. 8), así como la igualdad de derechos sociales y del acceso a la justicia (artículo 6) constituyen cambios que suponen una situación jurídica sustancialmente más favorable para los niños y las niñas migrantes.

Sin embargo, varias investigaciones y trabajos de organizaciones de la sociedad civil han mostrado que la persistencia de la exigencia de Documento Nacional Argentino (DNI) atenta contra el acceso a los derechos mencionados ${ }^{30}$; En la práctica muchos establecimientos educativos siguen solicitando DNI para la inscripción definitiva o para el otorgamiento de títulos y certificados de egreso; los establecimientos de salud mantienen por regla el requisito de presentar DNI para la atención, en particular para aquella programada (no emergencia). Se registran, igualmente, algunas prácticas positivas: el Ministerio de salud, a partir de su participación en la Mesa de Salud coordinada por UNLa y UNICEF, retiró la exigencia de DNI como único medio para inscribirse al Plan Nacer/SUMAR: desde 2012 las personas extranjeras pueden acceder al programa con la documentación de su país de origen.

De igual manera, la obligación del Estado de garantizar la vida familiar (artículos 3 y 10) da un marco jurídico protector de la infancia migrante y de los hijos e hijas de migrantes, tanto para permitir su ingreso al país y residencia como para evitar que algunas decisiones (por ejemplo, la expulsión) impliquen la separación de la familia. De hecho, se prevé un criterio de radicación por familia y para el pedido de residencia de una persona menor de 18 años alcanza la presentación y autorización de uno de sus padres/madres o tutor.

Por otra parte, en materia de control migratorio la ley brinda ciertos mecanismos favorables para la protección de la familia y la no separación de hijos y padres/madres. Por ejemplo, al regular algunas causales que podrían derivar en la cancelación de la residencia y posterior expulsión del país (por comisión de ciertos delitos u otras causales), se señala que dicha sanción no debería ser aplicada en caso de que la persona sea padre (madre), hijo o cónyuge de una persona de nacionalidad argentina, aunque dicha disposición no impediría la expulsión y, consecuentemente, la separación familiar (art. 62). En cuanto a la detención de migrantes en el marco de un procedimiento de expulsión, se prevé que la medida de expulsión puede suspenderse y en caso de acreditarse dicho vínculo familiar, se la deberá liberar de manera inmediata. Por lo tanto (aunque con la limitación señalada de la referencia a familiar de "argentino"), la protección familiar puede determinar la no aplicación de medidas de detención y expulsión.

${ }^{30}$ UNLa-UNICEF. Niñez, migraciones y derechos humanos en Argentina. IPPDH. Acceso a derechos de migrantes en la Provincia de Buenos Aires. 
Fuera de esto, estas normas omiten considerar de manera específica a NNA al regular ciertos aspectos de la residencia en el país y de los procedimientos migratorios. En particular, del texto de la ley surge que algunos derechos o estándares internacionales que se aplican a la niñez, y cuya fuente principal es la CDN, no fueron tenidos en cuenta; por ejemplo, al regular las causales de expulsión y el procedimiento para su ejecución, incluida la cuestión de la excepcional detención cautelar durante dicho proceso, no se ha incluido ninguna mención específica sobre la situación de niños/as que pudieran verse afectados por ese procedimiento.

Tampoco se ha establecido expresamente una excepción que impida, por un lado, la detención de niños/as migrantes por razones administrativas (por ejemplo, por falta de residencia regular), y por otro, su expulsión del país como consecuencia de la aplicación de una sanción. Siguiendo los estándares internacionales, la repatriación de niños/as (no acompañados o junto a sus familias) debería decidirse analizando el interés superior en cada caso, con el objetivo de proteger sus derechos.

Por otra parte, el derecho de todo/a niño/a a ser oído, otro principio central de la CDN, no parece haber sido especialmente considerado al momento de diseñar los procedimientos migratorios (de admisión, residencia y expulsión), de modo de asegurar su adecuada participación en los procesos que los afecten, como podría ser la eventual expulsión de sus padres o de toda la familia. Por supuesto, de allí no se deduce que en la práctica ese derecho no pueda garantizarse, pero indudablemente una protección explicitada en la ley hubiese contribuido sustancialmente al diseño de mecanismos que aseguren su ejercicio en todos los procedimientos que corresponda, de acuerdo con la edad y madurez del niño/a o adolescente. En varios casos judiciales sobre migración tramitados en la Capital Federal donde surgía del expediente la existencia de hijos e hijas menores, además de no privilegiar la unidad familiar sobre la expulsión, tampoco se convocó a los chicos a expresar su punto de vista; en los pocos casos que se conocieron donde los hijos pidieron ser oídos en la expulsión de su padre, el juez denegó el pedido "por no ser parte en el expediente"31.

De la misma manera, no se prevén mecanismos para hacer posible la intervención de autoridades u organismos en materia de infancia - de manera exclusiva o en coordinación con la DNM - en casos relativos a NNA. Esta omisión puede repercutir en la falta de un enfoque centrado en la niñez y sus derechos. Por ejemplo, el INCUCAI (organismo nacional de trasplantes) deniega por

${ }^{31}$ GARCIA, Lila. Nueva política migratoria y derechos de la movilidad. 
regla general la solicitud de inscripción en las listas de espera para las personas extranjeras que no tienen residencia permanente. Esto ha provocado varios casos judiciales donde la inscripción se logró vía orden del juez.

Por último, una práctica positiva es la del Protocolo para la protección, asistencia y búsqueda de soluciones duraderas para los niños no acompañados o separados de sus familias. Este documento fue elaborado desde un espacio de trabajo conformado por varias instituciones ${ }^{32}$ y validado en el contexto de las mesas interinstitucionales de trabajo coordinadas por la Universidad Nacional de Lanús y UNICEF Argentina. En sí, el trabajo en distintas mesas de trabajo (sólo para nombrar las coordinadas por UNLa y UNICEF: de "Salud, niñez y migración"; de "Educación, niñez y migración" y de "Adecuación normativa y prevención de la xenofobia") ha sido una experiencia positiva en múltiples aspectos: encuentro de actores, discusión de casos y situaciones, articulación de políticas, conformación de agendas comunes y producción de materiales ${ }^{33}$. Sobre este último aspecto, uno de los trabajos más valiosos está formado por la "Valija de materiales para trabajar la inmigración en y desde la escuela", realizado en conjunto con el Ministerio de Educación nacional y otras instituciones, destinado a docentes y alumnos de escuelas de primera y segunda enseñanza ${ }^{34}$.

\section{Reflexiones finales}

Esta reseña es sólo un brevísimo panorama de la situación de los derechos de NNA en el contexto de la migración de América Latina y el Caribe, con base en principios y estándares que se derivan de la Convención sobre Derechos del Niño. El escenario actual revela algunos avances a destacar, pero también una serie de desafíos que requieren el desarrollo de numerosas políticas públicas en la materia, incluyendo reformas normativas en muchos casos.

En este contexto, es importante señalar que seguramente antes de mediados de 2014, la Corte Interamericana de Derechos Humanos emitirá la Opinión Consultiva sobre derechos de la niñez en el contexto de la migración. Se destaca que su solicitud fue hecha de forma conjunta por los cuatro países miembros del MERCOSUR, representando una iniciativa sin precedentes que muestra la especial relevancia del tema para la vigencia de los derechos humanos en la región y un posicionamiento común del bloque

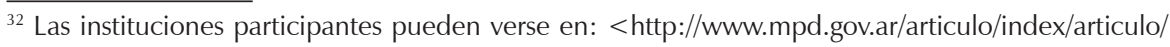
protocolo-para-los-ni-os-no-acompa-ados-o-separados-de-sus-familias-en-busca-de-asilo-953>.

${ }_{33}$ Más sobre las mesas, en UNLa-UNICEF. Niñez, migraciones..., op. cit.

${ }^{34}$ Disponible en: <http://valijainmigracion.educ.ar/>.
} 
subregiona ${ }^{35}$. El proyecto de la OC fue discutido y consensuado - luego de un intenso proceso de consulta a diversos actores - en el seno de la Comisión Permanente Iniciativa Niñ@Sur, por los representantes de los países miembros del MERCOSUR, y contó con la adhesión de los representantes de los países asociados.

En el marco de este proceso se realizaron una audiencia en México en octubre de 2013 y se presentaron gran variedad de Amici Curiae, en la que diversos actores, a la par de solicitar un pronunciamiento a la Corte, expresaron su interpretación sobre diversas cuestiones centrales, a los fines de avanzar en los desafíos pendientes en materia de adecuación de las políticas publicas para lograr la plena vigencia de los derechos y garantías de los NNA migrantes. En este sentido, se destaca el escrito presentado por $\mathrm{UNICEF}^{36}$, el cual pone énfasis en la preeminencia del marco jurídico sobre protección y promoción de derechos de NNA de infancia sobre las políticas migratorias, determinando que en caso de conflicto, siempre debe primar la CDN y las normas constitucionales y legales de los sistemas de protección de la infancia.

Esta OC puede llegar a ser una herramienta trascendental para promover y garantizar la protección de los derechos humanos y consolidar estándares de derechos aplicables a los NNA migrantes y sus familias. Por otra parte pude tener un impacto importantísimo para fijar directrices sobre las obligaciones de los estados en la región en los términos de adecuación normativa, fijando límites para las políticas de control migratorio y, en definitiva, promoviendo la debida primacía de la protección integral de los derechos de los niños, niñas y adolescentes.

Ello podría derivar en el desarrollo de iniciativas que conduzcan a las reformas políticas y normativas dirigidas a garantizar los derechos de NNA migrantes así como de hijos e hijas de migrantes. De ahí se podría contribuir a un desafío aún mayor: abordar de manera integral - con medidas de corto, mediano y largo plazo - las causas estructurales que empujan a millones de NNA y/o sus padres a salir de su país.

\section{Bibliografía}

ACNUR. Children on the Run. Unaccompanied Children Leaving Central America and Mexico and the Need for International Protection. Washington, 2014. APPLESEED MEXICO. Niños en la Frontera: Evaluación, Protección y Repatriación de

\footnotetext{
35 Para más información sobre sus antecedentes consultar: DIÁLOGO entre la Iniciativa Niñ@Sur y los Sistemas Universal e Interamericano de Protección de Derechos Humanos. Publicación de Iniciativa Niñ@Sur, 2011, p. 94 a 102.

${ }^{36}$ OBSERVACIÓN Escrita de UNICEF sobre Niñez Migrante en América Latina y el Caribe, op. cit.
} 
Niños, Niñas y Adolescentes Mexicanos sin Compañía, Mexico 2011. Disponible en: <https://www.appleseednetwork.org/mexicoappleseed/publicaciones/>.

CASA ALIANZA. Análisis de la situación de Derechos de la Infancia Migrante No Acompañada en el marco de los procedimientos de deportación y retorno a Honduras. Tegucigalpa, junio de 2012.

CASTLES, Stephen; MILLER, Thomas. La era de la migración. Movimientos internacionales de población en el mundo moderno. Mexico: INM-Universidad de Zacatecas-Porrúa, 2004.

CATHOLIC RELIEF SERVICES. Niñez migrante. Detención y repatriación desde México de niños, niñas y adolescentes centroamericanos no acompañados. Informe de investigación. Baltimore, Enero de 2010.

CEPAL. Migración Internacional, derechos humanos y desarrollo. Santiago de Chile: CEPAL-CELADE, 2006.

CERIANI CERNADAS, Pablo. Luces y sombras en la legislación migratoria latinoamericana. Revista Nueva Sociedad, n. 233, 2011, p. 68-86.

(coord.). Niñez Detenida. Los derechos de los niños, niñas y adolescentes migrantes en la frontera México-Guatemala. Lanus y Mexico: Fontamara, 2013. Disponible en: < http://ninezmigrante.blogspot.com.ar/>.

. Migraciones y el Derecho a la vida familiar de niños, niñas y adolescentes. Revista Población, n. 10, Buenos Aires, p. 81-92.

GARCÍA, Lila. Nueva política migratoria y derechos de la movilidad. Implementación y desafíos de una política basada en derechos humanos a través de las acciones ante el Poder Judicial (2004-2010). Tesis doctoral, Facultad de Derecho, Universidad de Buenos Aires, mimeo, 2013.

GIL ARAUJO, Sandra. Las periferias de la metrópolis. Políticas migratorias, género y estratificación de la población latinoamericana en España. Mélanges de la Casa de Velázquez. Nouvelle série, v. 39, n. 1, 2009, p. 57-74.

INSTITUTO DE POLÍTICAS PÚBLICAS DE DERECHOS HUMANOS DEL MERCOSUR (IPPDH). Acceso a derechos de migrantes en la Provincia de Buenos Aires. Buenos Aires: IPPDH, 2013.

IZQUIERDO, Antonio. Cuatro razones para pensar en la inmigración irregular. In BLANCO, María Cristina (ed.). Migraciones. Nuevas movilidades en un mundo en movimiento. Barcelona: Anthropos, 2006.

ORGANIZACIÓN INTERNACIONAL PARA LAS MIGRACIONES (OIM). El futuro de la migración: creación de capacidades para el cambio. Binebra: OIM, 2010.

UNLa-UNICEF. Niñez, migraciones y derechos humanos en Argentina. Estudio a diez años de la ley de migraciones. Buenos Aires: EDUNLa, 2013.

. Estudio sobre los estándares jurídicos básicos aplicables a niños y niñas migrantes en situación migratoria irregular en América Latina y el Caribe. Lanús: EDUNLa, 2009. Disponible en: <http://www.unicef.org/mexico/spanish/mx_ Unicef-EstandaresJuricoNyNMigrantes.pdf $>$. 
WOMEN'S REFUGEE COMMISSION. Informe Forced From Home: The Lost Boys and Girls of Central America. 2012. Disponible en: < http://www.youthtoday.org/ hotdocs/Forced\%20From\%20Home1.pdf >.

ZLOTNIK, Hania. Tendencias de la migración internacional desde 1980. In BLANCO, Cristina. Migraciones. Nuevas movilidades en un mundo en movimiento. Barcelona: Anthropos, 2006.

\section{Abstract \\ Childhood and adolescence in the context of migration: principles, advancements, and challenges for protecting their rights in Latin America and the Caribbean}

The present article strives to give a panorama of the situation of youth in Latin America and the Caribbean, especially regarding the current advancements and challenges facing the region's countries on the issue of the human rights of children and adolescents (NNA) in the context of immigration. With such an end, the article forms a general description based upon certain broad principles derived from the Convention of the Rights of the Child, upon which can be constructed some concrete standards applicable to NNA migrants and their children. We present two timely cases which succinctly and precisely cover the variety of contexts, opportunities, and challenges within the region: Argentina and Mexico.

Keywords: migration, human rights, children, Latin America.

Recebido para publicación en 17/03/2014.

Aceptado para publicación en 29/05/2014.

Received for publication in March, 17 $7^{\text {th }}, 2014$.

Accepted for publication in May, 29 2014.

ISSN impresso: 1980-8585

ISSN eletrônico: 2237-9843 